\title{
The Business Management Knowledge Needs of Physicians: and Online Education
}

\section{Lionel S de Souza*}

2781 State Route 746, Cardington, Ohio 43315, USA

\begin{abstract}
The health-care industry in the United States is constantly being altered with new legislation, globalization and informed consumers representing the forces of transformational change. Medical practitioners are realizing that their training and knowledge acquired in medical school is proving inadequate to handle the newer business and competitive pressures. Business management and marketing skills are becoming necessary to efficiently manage, maintain, and grow physician practices. This exploratory research study involved a diverse sample of practicing and administrative physicians, to examine the degree at which change is making it imperative for a medical practitioner to learn and acquire these competencies. The analysis of a survey administered to physicians included using the quantitative data analytical technique of correlation. A notable response to the survey indicated that $76.9 \%(40)$ of respondents either strongly agreed or agreed that the convenience and asynchronous nature of online education could serve their business educational needs since time is at a premium.
\end{abstract}

Keywords: Business; Management knowledge; Online education

\section{Introduction}

Recent upheavals in the US healthcare system, coupled with globalization and transformational change caused by technology and more informed consumers have altered the industry [1]. Medical practitioners in private, group practice, and serving in institutions are finding that newer business management and marketing skills are becoming necessary. To efficiently manage, maintain, grow practices, university level business education is a potential solution to bridging this deficit $[2,3]$.

Many physicians are finding that their medical training and knowledge acquired in their years of medical school are proving inadequate to handle the newer business and competitive pressures imposed by a changing environment. In the changing healthcare environment, physicians face challenges to display business and leadership skills in improving and sustaining medical practices [4]. Physicians must manage practices efficiently and there a multiplicity of other issues to contend with, including liability and insurance [5]. To add to the pressures of increasing and sustaining practices, healthcare laws are complicated and detract from a purely clinical focus [6]. In examining change in the industry, one of the forces shaping the industry is informed and knowledgeable consumers and patients [7]. Customer relationship management, business and marketing knowledge are vital for building private and institutional businesses.

Medical practitioners in private practice, group practices, and in institutional settings are finding that newer business, management, and marketing skills are becoming necessary to attract and retain patients. Extensive and detailed literature review and industry analysis indicated that this need for physician business education exists. This study being exploratory in nature, there was no testing of hypotheses. The focus of this exploratory research study included examining how web-based delivery of business education could meet physician's needs as they are severely time constrained. The rationale for the computer mediated online education appears supported by physician web connectivity and strong preference for the internet for many clinical and personal needs [8].

Among other important findings from research undertaken for the study, were that physicians of all ages were spending more time online for personal and professional work and activities. The most important benefit of asynchronous computer-mediated delivery of online or webbased education is that it seems ideally suited for busy individuals, and study and coursework completed irrespective of geography and time. The views from [9] may reinforce the purpose of the study and also provide supportive arguments in favor of online education being a logical choice, when time is a factor to be considered, as traditional methodologies do not fit easily into busy schedules and do not support studying at one's own pace to meet personal learning requirements [9].

The following overarching research question may signify the exploratory intent of this study: To what extent are changes in health-care environment making it imperative for physicians to learn and acquire new skills in Business Management, Marketing, Financial Management and Leadership? The significance of the study is that it may provide further insight into physician business management educational needs in the wake of changes in the health care-environment and the consequent and associated implications of successfully managing and growing physician practices, in both private and institutional settings. A survey of graduating medical students suggested discontent in the inadequate knowledge they received on medical economics, practice management [10], managed care, costeffective medical practice and other areas [11].

The paucity and absence of research on the subject of physician training related to non-medical education notwithstanding, an extensive and detailed literature review undertaken, provided insight on important topics, concepts and strategies related to the focus of this research. Physician leadership is a highly desirable skill for the success of medical groups, a recent trend under the new climate of managed care and reimbursement, and leadership often a part of business curricula. Medical groups can gain from and learn from other businesses and leadership and is a critical success factor in these settings [12]. The need for leadership development in clinical practice has been found to be an imperative under a changing healthcare system, [13]. The ongoing

*Corresponding author: Lionel S de Souza, 2781 State Route 746, Cardington, Ohio 43315, USA, Tel: 419864 0226; E-mail: lioneldesouza@hotmail.com

Received January 01, 2015; Accepted January 27, 2015; Published February 07, 2015

Citation: Souza LS (2015) The Business Management Knowledge Needs of Physicians: and Online Education. Int J Econ Manag Sci 4: 229. doi:10.4172/21626359.1000229

Copyright: ( 2015 Souza LS. This is an open-access article distributed under the terms of the Creative Commons Attribution License, which permits unrestricted use, distribution, and reproduction in any medium, provided the original author and source are credited. 
quest for improved performance in public health is reason that supported arguments suggesting the need for physician professional and leadership development [14]. Lifelong learning is the goal of public health workforce development, and leadership development is part of that learning since it gives the tools to make public health practice more effective and strengthen the structure of the public health system [15].

The pressures of achieving cost benefits are strong in innovative care management [16]. With survival being a key factor, under the ever changing arena of managed care and funding shortages, learning from the successful practices of the business world is vital [17]. Acquiring these business skills require studying business and management courses and a critical success factor for organizations may lie in managing people effectively with lean operations. To attract and retain physicians, marketing and human resources knowledge is critical are critical [18].

In individual practice settings, success is contingent on good business and leadership, and inculcated and developed through training and education [17] suggested institutions must manage these challenges of managed care and funding deficits shortages by learning from successful business practices. To summarize, online institutions may be able to offer physicians and health care professionals, content specific and quality educational and other physician business management development programs.

\section{Methods}

The appropriateness and rationale of exploratory research for this study derived support from views expressed in literature favoring continuous improvement and ongoing learning as being mandatory for physicians, in an era of disconcerting change. The propensity of physicians to acquire and enhance these skills through educational courses does not appear to be widely studied. The exploratory outlook of this research study may suggest potential contribution to the existing body of sparse knowledge on physician online business education. The structure of exploratory studies are oriented towards developing hypotheses or questions that lay the foundation for further research [19].

The goal of attaining adequate sample size was by administering the research instrument to randomly selected, geographically dispersed physicians. The selecting and screening of physicians completing the questionnaire for the purpose of this study included the criteria of being board certified, registered and licensed as medical practitioners. Physicians with administrative responsibilities were also included in the study. For determining and evaluating correlation among practices etc., the research instruments included pre-determined eligibility criteria.

After the initial development of the research instrument, it was pilot tested by a physician panel and consistent with the goals this exploratory research, administered to 60 physicians, randomly selected from private practice and administrative settings. Random sampling was favored to offer equal chance of selection of every individual in the population [20].

To indicate the purpose and nature of the study and minimize bias, the survey questionnaire commenced with a short introductory description of the study. Since this was exploratory research, the research instrument was also interspersed with open-ended questions to generate deep insight, perceptions, and views on any aspect of the research that the respondents wished to express opinions about. The analytical software SPSS was utilized for its multi-dimensional advanced analytical capabilities, which facilitated the examination of data in a variety of different ways, conjointly with the capabilities of Excel. The conversion of collected data into table format for cross tabulation facilitated data analysis and the examining of relationship between the variables [21].

Performing detailed analysis prevented the making of speculative assumptions and involved the assessment of the correlation between the various variables and factors. The correlation between two variables appears evident when a change in the value of one signifies a change in the other. The most common measure of correlation is the Pearson coefficient of correlation, which measures the relationship between two variables. The selection of statistics and measures of association received careful consideration, including the invocation of Spearman's measure of correlation to measure correlation for ordinal data [20]. The favorability of Kendall's tau_b similarly stemmed for its utility in analyzing paired observations (Appendix A and B).

\section{Results}

A survey was first developed using a panel of experts comprising of five physicians. A finalized survey resulted from detailed iterations with the expert panel, who then further piloted its testing, by completing the survey, although excluded from the main study to maintain research rigor. The reasons prompting the testing of the survey included relevance of content, ease of completion and navigation, optimal length, and other pertinent factors associated with an online survey, to also facilitate accuracy and drive response rate. After this initial pilot testing, the administering of the web-based survey to physicians, selected randomly from diverse practice and administrative settings completed the data collection.

The availability of the survey for a period of 60 days seemed adequate using Survey Monkey, an online organization offering secure survey hosting capabilities and intelligent survey software, which further enabled the creation of a professional online survey, quickly and easily. Invitations to participants included utilizing the survey link to the survey. The powerful filtering capabilities in addition displayed responses and facilitated downloading the raw data into Excel, which made possible the manual transference to SPSS for further statistical analysis. The presentation below includes a detailed analysis of each question of the survey and discussion of the interpretation:

Research Question 1: How are changes in the health-care environment making it imperative for physicians to learn and acquire new skills in Business Management, Business Administration, Financial Management, Leadership, and Information Management?

The total number of physician respondents $(\mathrm{N}=60$, with 8 individuals skipped question) $76.9 \%$ (40) of respondents either strongly agreed or agreed, that changes in the health-care environment are making it imperative for physicians to learn and acquire new skills in Business Management, Business Administration, Financial Management, Leadership, and Information Management. There were no disagreements with this premise, and while $7.7 \%$ (4) respondents were neutral, $15.4 \%$ (8), respondents disagreed.

To generate examine measures of association, Pearson Correlation, Kendall's tau_b, and Spearman's rho tests were utilized. The Pearson correlation coefficient, $r$, is a measure of linear association between the variables, while the Spearman's correlation coefficient, rho, measures association between rank orders, when both table variables (factors) are quantitative. Since both rows and columns in the data contain ordered 
values, the analysis included Kendall's tau-b for evidence of association. Applying the criteria that coefficients of association vary from 0 (indicating no relationship) to 1 (indicating perfect relationship) or -1 (indicating perfect negative relationship), there was a weak relationship as seen in Table 1, between practice type to this question with Pearson Correlation only, of $-.280\left({ }^{*}\right)^{*}$ at the 0.05 level (2-tailed). The strong consensus seemed to be, that acquiring these skills were essential in an era of health-care change. Even experienced physicians felt the same, as tenure did not influence any difference in opinion and yielded a perfect .000 indicative of no relationship as evinced through Pearson's Correlation, and Kendall's tau_b, and Spearman's rho respectively, in Tables 1 and 2, also signifying that learning can occur at any age and stage of professional life.

Research Question 2. How important do you feel that changes in health-care environment are making it imperative for physicians to learn and acquire new skills in: Business Management, Marketing, Financial Management and Leadership through educational/training programs or specialized courses?

In response to this question, $69.3 \%$ (36) felt that it was either important or very important to acquire new skills. Only a small percentage of $15.4 \%$ (8) felt it being unimportant, and no respondent thought it to be very unimportant, thereby testifying to the large belief that there is change and decisive action to negotiate the forces of change are crucial. From Tables 3 and 4, no noteworthy correlations appeared evident.
Research Statement 3: Please rank in order of importance from the list below, the educational platform or method you feel would contribute most to enhancing physician's skills and knowledge in business that could help in better managing and growing practices. Please rank in order of importance, with " 1 " being of most importance, "2" being of next most importance, etc.

In this ranking online education ranked highest: with $31 \%$ and then third: with $38 \%$, in choice by physicians of all practice types from among the 52 respondents who completed this question. Seminars and conferences on business garnered the second highest ranking of $43 \%$. Contrary to what may seem as logical, educational courses in business management offered through traditional Business Schools and Universities actually could only muster $29 \%$, and ranked fourth in overall choice, thus speaking of the importance for flexibility and asynchronous formats as a match for meeting these needs, in the eyes of physicians.

Research Question 4: Which of the following courses do you feel represent the knowledge that is important in the current health environment from a non-medical point of view? Please rank these courses in order of importance, with " 1 " being of most importance, " 2 " being of next most importance, etc.

The first and third rakings were for Business Management courses with $31 \%$, and $38 \%$ respectively. Also consistent with literature review and other analysis conducted, Marketing and Leadership courses

\begin{tabular}{|l|l|c|c|c|c|}
\hline & & GENDER & B.CERT & PRA.TYPE & AGE \\
\hline Q.1 & Pearson Correlation & -0.256 & 0.27 & $-.280\left(^{*}\right)$ & -0.209 \\
\hline & Sig. (2-tailed) & $0.067^{* *}$ & 0.053 & 0.045 & 0.137 \\
\hline & N & 52 & 52 & 52 & 52 \\
\hline
\end{tabular}

${ }^{* *}$ Correlation is significant at the 0.01 level (2-tailed). ${ }^{*}$ Correlation is significant at the 0.05 level (2-tailed).

Table 1: Correlations: Change making it imperative for physicians to acquire new skills in Business, using Pearson's Measure of Correlation.

\begin{tabular}{|c|c|c|c|c|c|c|c|}
\hline & & & GENDER & B.CERT & PRA.TYPE & AGE & TENURE \\
\hline \multirow[t]{3}{*}{ Kendall's tau_b } & \multirow[t]{3}{*}{ Q.1 } & Correlation Coefficient & -0.201 & 0.17 & -0.218 & -0.158 & 0 \\
\hline & & Sig. (2-tailed) & 0.127 & 0.197 & $0.075^{*}$ & 0.189 & 1 \\
\hline & & $\mathrm{N}$ & 52 & 52 & 52 & 52 & 52 \\
\hline \multirow[t]{3}{*}{ Spearman's rho } & \multirow[t]{3}{*}{ Q.1 } & Correlation Coefficient & $-0.214^{\star *}$ & 0.181 & -0.262 & -0.194 & 0 \\
\hline & & Sig. (2-tailed) & 0.128 & 0.2 & 0.06 & 0.169 & 1 \\
\hline & & $\mathrm{N}$ & 52 & 52 & 52 & 52 & 52 \\
\hline
\end{tabular}

** Correlation is significant at the 0.01 level (2-tailed). ${ }^{*}$ Correlation is significant at the 0.05 level (2-tailed).

Table 2: Correlations: Change making it imperative for physicians to acquire new skills in Business, using Kendall's tau_b Spearman's rho Measures of Correlation.

\begin{tabular}{|l|l|c|c|c|c|}
\hline & & GENDER & B.CERT & PRA.TYPE & AGE \\
\hline Q.2 & Pearson Correlation & -0.21 & 0.222 & $-.275\left(^{*}\right)$ & -0.195 \\
\hline & Sig. (2-tailed) & $0.136^{* *}$ & 0.114 & $0.048^{*}$ & 0.129 \\
\hline & N & 52 & 52 & 52 & 52 \\
\hline
\end{tabular}

** Correlation is significant at the 0.01 level (2-tailed). * Correlation is significant at the 0.05 level (2-tailed).

Table 3: Correlations: Perceived importance of changes in health-care environment making it imperative for physicians to learn and acquire new skills in Business through education, using Pearson's Measure of Correlation.

\begin{tabular}{|l|l|l|c|c|c|}
\hline & & & GENDER & B.CERT & PRA.TYPE \\
\hline Kendall's tau_b & \multirow{2}{*}{ Q.2 } & Correlation Coefficient & -0.141 & 0.159 & -0.188 \\
\cline { 3 - 6 } & & Sig. (2-tailed) & $0.274^{* *}$ & 0.217 & 0.119 \\
\cline { 2 - 5 } & & 52 & 52 & 52 \\
\hline
\end{tabular}

${ }^{* *}$ Correlation is significant at the 0.01 level (2-tailed). ${ }^{*}$ Correlation is significant at the 0.05 level (2-tailed).

Table 4: Correlations: Perceived importance of changes in health-care environment making it imperative for physicians to learn and acquire new skills in Business through education, using Kendall's tau_b and Spearman's rho Measures of Correlation. 


\begin{tabular}{|l|l|c|c|c|c|}
\hline & & GENDER & B.CERT & PRA.TYPE & AGE \\
\hline Q.5 & Pearson Correlation & $.441\left(^{* *}\right)$ & 0.175 & 0.023 & $.276\left(^{*}\right)$ \\
\hline & Sig. (2-tailed) & 0.001 & 0.213 & 0.87 & $-.512\left(^{* *}\right)$ \\
\hline & N & 52 & 52 & 52 & 0.047 \\
\hline
\end{tabular}

${ }^{* *}$ Correlation is significant at the 0.01 level (2-tailed). ${ }^{*}$ Correlation is significant at the 0.05 level (2-tailed).

Table 5: Correlations: Type and nature of courses: Degree Program, Non-Degree Course, Professional Certification, Other (please specify) using Pearson's Measure of Correlation.

\begin{tabular}{|c|c|c|c|c|c|c|c|}
\hline & & & GENDER & B.CERT & PRA.TYPE & AGE & TENURE \\
\hline \multirow[t]{3}{*}{ Kendall's tau_b } & \multirow[t]{3}{*}{ Q.5 } & Correlation Coefficient & $.391\left({ }^{* *}\right)$ & 0.156 & -0.017 & 0.129 & $-.458(* *)$ \\
\hline & & Sig. (2-tailed) & 0.002 & 0.224 & 0.889 & 0.272 & 0 \\
\hline & & $\mathrm{N}$ & 52 & 52 & 52 & 52 & 52 \\
\hline \multirow[t]{3}{*}{ Spearman's rho } & \multirow[t]{3}{*}{ Q.5 } & Correlation Coefficient & $.428\left({ }^{\star *}\right)$ & 0.17 & -0.005 & 0.231 & $-.516\left({ }^{*}\right)$ \\
\hline & & Sig. (2-tailed) & 0.002 & 0.228 & 0.975 & 0.099 & 0 \\
\hline & & $\mathrm{N}$ & 52 & 52 & 52 & 52 & 52 \\
\hline
\end{tabular}

${ }^{* *}$ Correlation is significant at the 0.01 level (2-tailed). ${ }^{*}$ Correlation is significant at the 0.05 level (2-tailed).

Table 6: Correlations: Type and nature of courses: Degree Program, Non-Degree Course, Professional Certification, Other (please specify) using Kendall's tau_b and Spearman's rho Measures of Correlation.

\begin{tabular}{|l|l|c|c|c|c|}
\hline & & GENDER & B.CERT & PRA.TYPE & AGE \\
\hline Q.6 & Pearson Correlation & 0.208 & -0.029 & 0.113 & $.553\left({ }^{* *}\right)$ \\
\hline & Sig. (2-tailed) & 0.139 & 0.837 & 0.423 & $-.342\left(^{*}\right)$ \\
\hline & N & 52 & 52 & 52 & 0.013 \\
\hline
\end{tabular}

${ }^{* *}$ Correlation is significant at the 0.01 level (2-tailed). ${ }^{*}$ Correlation is significant at the 0.05 level (2-tailed).

Table 7: Correlations: Ideal level of courses, using Pearson's Measure of Correlation.

\begin{tabular}{|c|c|c|c|c|c|c|c|}
\hline & & & GENDER & B.CERT & PRA.TYPE & AGE & TENURE \\
\hline \multirow[t]{3}{*}{ Kendall's tau_b } & \multirow[t]{3}{*}{ Q.6 } & Correlation Coefficient & 0.209 & -0.02 & 0.05 & $.472\left({ }^{* *}\right)$ & $-.301\left(^{*}\right)$ \\
\hline & & Sig. (2-tailed) & 0.104 & 0.879 & 0.674 & 0 & 0.015 \\
\hline & & $\mathrm{N}$ & 52 & 52 & 52 & 52 & 52 \\
\hline \multirow[t]{3}{*}{ Spearman's rho } & \multirow[t]{3}{*}{ Q.6 } & Correlation Coefficient & 0.228 & -0.021 & 0.074 & $.539\left(^{* \star}\right)$ & $-.365\left(^{* *}\right)$ \\
\hline & & Sig. (2-tailed) & 0.105 & 0.88 & 0.602 & 0 & 0.008 \\
\hline & & $\mathrm{N}$ & 52 & 52 & 52 & 52 & 52 \\
\hline
\end{tabular}

${ }^{* *}$ Correlation is significant at the 0.01 level (2-tailed). ${ }^{*}$ Correlation is significant at the 0.05 level (2-tailed).

Table 8: Correlations: Ideal level of courses, using Kendall's tau_b and Spearman's rho Measures of Correlation.

tied as second choice with $29 \%$ apiece in this survey, reinforcing the view that marketing and leadership are essential to manage and grow practices. The importance of Financial Management and Information study seemed relegated to lower importance, and made sense since many organizations favor the outsourcing of these functions to specialist firms, or in case of large and institutional practices, specialist accounting and IT departments manage these functions. Furthermore, the availability of user-friendly and customizable software possibly reduced the perceived importance of these two courses.

Research Question 5: In your opinion, should these courses be part of a: Degree Program, Non-Degree Course, Professional Certification, Other? (Please specify)

The general outlook indicated a leading preference for non-degree courses, with a $30.8 \%$ margin, and the others comprising of Degree Program, Professional Certification, and Other, were tied with $21.3 \%$. From this data, the inference may be, that the type of course or program is immaterial, education on these fronts are vital, period. In analyzing a positive, albeit weak correlation in Tables 5 and 6, between the gender and this question, there appeared to really show no distinction between male and female in the overall picture. The notable difference in choices made by each gender appeared pronounced as females $50 \%$ (8) deemed 'other' as top choice, and 25\% saw non-degree as being important, with the other $25 \%$ not responding at all. Males expressed equal preference of $30 \%$ for the three options, with $10 \%$ for other.

Since age exhibited a positive $.276\left(^{*}\right)$ correlation in Table 5, significant at the 0.05 level (2-tailed), interestingly in the 25-35 age group, the choice was $50 \%$ in favor of non-degree programs and $25 \%$ favoring professional, and other respectively. This may be suggestive, that in case of younger respondents who have more recently completed structured and regimented degree programs in medical education, and their choice now was more in favor of non-degree programs. Conversely, with several years behind their earned degree, the more advanced age group of 36-45 years, were inclined to opt for a degree for their effort, with $50 \%$ favoring a degree and $33.3 \%$ a non-degree, and $16.7 \%$ choosing not to answer.

Research Question 6: In your opinion, should these courses be best at the following level. Please select one that represents your choice: Associate, Bachelors, Masters, or Other?

The type of degree perceived as being relatively unimportant by participants, stemmed from their placing greater importance to the quality of education in business as what really matters. In this context, $30.8 \%$ favored Associated and other as leading choices. Masters was $23.1 \%$ and a Bachelor's degree rated $15.4 \%$. Relationships if any, viewed through the different measures of correlation, were at best weak as seen in Tables 7 and 8 respectively. 


\begin{tabular}{|l|l|c|c|c|c|}
\hline & & GENDER & B.CERT & PRA.TYPE & AGE \\
\hline Q.7 & Pearson Correlation & 0.24 & 0.049 & 0.204 & 0.085 \\
\hline & Sig. (2-tailed) & $0.087^{* *}$ & 0.729 & 0.147 & $0.549^{*}$ \\
\hline & N & 52 & 52 & 52 & 52 \\
\hline
\end{tabular}

${ }^{* *}$ Correlation is significant at the 0.01 level (2-tailed). ${ }^{*}$ Correlation is significant at the 0.05 level (2-tailed).

Table 9: Correlations: Ideal length of courses, using Pearson's Measure of Correlation.

\begin{tabular}{|c|c|c|c|c|c|c|c|}
\hline & & & GENDER & B.CERT & PRA.TYPE & AGE & TENURE \\
\hline \multirow[t]{3}{*}{ Kendall's tau_b } & \multirow[t]{3}{*}{ Q.7 } & Correlation Coefficient & 0.234 & $0.059^{*}$ & 0.153 & 0.148 & 0 \\
\hline & & Sig. (2-tailed) & 0.069 & 0.644 & 0.203 & 0.21 & 1 \\
\hline & & $\mathrm{N}$ & 52 & 52 & 52 & 52 & 52 \\
\hline \multirow[t]{3}{*}{ Spearman's rho } & \multirow[t]{3}{*}{ Q.7 } & Correlation Coefficient & 0.255 & 0.065 & 0.172 & 0.186 & 0 \\
\hline & & Sig. (2-tailed) & $0.068^{* *}$ & 0.649 & 0.222 & 0.186 & 1 \\
\hline & & $\mathrm{N}$ & 52 & 52 & 52 & 52 & 52 \\
\hline
\end{tabular}

${ }^{* *}$ Correlation is significant at the 0.01 level (2-tailed). ${ }^{*}$ Correlation is significant at the 0.05 level (2-tailed).

Table 10: Correlations: Ideal length of courses, using Kendall's tau_b and Spearman's rho Measures of Correlation.

Research Question 7: Since physicians are busy professionals who are often severely constrained by time, in your opinion, what would be the ideal length of a course that would allow for busy schedules without compromising educational quality or rigor?

There was no significant correlation of variables to this question as seen from Tables 9 and 10. The five-week course was highly favored by $38.5 \%$, and $30.8 \%$ choosing other. The duration of the 8 week course was seen as less than ideal, with a $15.4 \%$ response rate, and even less desirable were the 6 or 9 week courses with a $7.7 \%$ favored rate. There were no responses at all for the seven week duration course.

Research Question 8: If a reputed or accredited Online University were to develop and provide high quality content and leading edge educational courses online for physicians, in non-medical fields of Business, Marketing, Financial Management, and Leadership, by virtue of their solid experience and expertise in these areas, please indicate the importance to you of the following:

In regards to course content and relevance, $100 \%$ of all respondents thought it as being very important or important. Insofar as convenient format to fit busy schedules, $85.7 \%$ endorsed its value, $14.3 \%$ were neutral, and there were no views against.

\section{Discussion}

The summarization here represents the major findings of this research study and details some of the important conclusions. The inferences and conclusions drawn may reflect evaluation of the major findings of the study, while concomitantly viewing the big picture of change in the health-care climate, and its impact on physicians, insofar as business knowledge is concerned. The degree and extent change in the health-care environment is making it imperative for physicians to learn and acquire new skills prompted extensive analysis and discussion of the suitability of online courses in relation to Business Management, Business Administration, Financial Management, Leadership, and Information Management. Convenience and the asynchronous nature of online courses received high favorability.

Through the physician survey, it thus became abundantly evident, that when $76.9 \%$ (40) of physician respondents either strongly agreed or agreed just to this question, there is an opportunity that needs further exploration and study. Physicians themselves seemed less enamored with academic accolades and their views were indicative, that it was more of "a means to an end," and hence in merely acquiring these business competencies. A manifestation of this notion, was in a leading expressed preference for non-degree courses, with a 30.8\% margin, and the others comprising of: Degree Program, Professional Certification, and Other; all being tied with $21.3 \%$. As was stated previously, from this data, surveyed physicians largely inferred that the type of course or program is immaterial, education in these areas is important to manage and improve practices.

\section{Synthesis}

Further research notwithstanding, in addition to lending credence to this opportunity, a variety of course offerings may actually be possible for online institutions to satisfy both degree credential pursuits, and the just business competency aspirations of physicians. The rationale for the online format appears overwhelming based on strong evidence from views expressed in literature and the findings of this study, which indicated strong physician preference for the internet, for many clinical and personal needs. Corroboration of this preference through this research study, suggests that computer mediated online education, executed through reputed online institutions is viable:

o A growing receptivity and acceptance of online education by none other than a high profile physician audience, who are so carefully trained to accept only after examining symptoms, conducting extensive tests, and are generally found making carefully considered decisions. Online was rated as being the optimal delivery platform by $31 \%$ of respondents, and then also third: with $38 \%$, in choice by physicians of all practice types from among the 52 of the physician respondents who completed this question, which could be seen as a commendable achievement.

o Equally impressive, is that online convenience trumped in preference over educational courses in business management offered through traditional business schools and universities, the latter could actually only muster the vote of $29 \%$ of respondents, and ranked fourth in overall choice of favored formats.

The above views speak on the importance of flexibility and asynchronous formats as a match for meeting these needs, as expressed by a participant: "The on-line environment allows for physicians to work study around their busy practice and personal lives so it is an ideal learning process." Insofar as the sentiments on convenient format to fit busy schedules, $85.7 \%$ of physician respondents viewed it as crucial, $14.3 \%$ were neutral, and there were no views against. 
Citation: Souza LS (2015) The Business Management Knowledge Needs of Physicians: and Online Education. Int J Econ Manag Sci 4: 229. doi:10.4172/2162-6359.1000229

Page 6 of 6

The convenience of the online format does give rise to another related question, on the ideal and optimal duration and length of these courses. There was little variance in opinions, as the five course was highly favored by $38.5 \%$ majority response of physicians over a slightly longer six week duration of the $34.2 \%$ respondents. The conclusion drawn, is that the focus of these courses would require specific customization for relevance to the health-care industry and to also sustain and captivate the interest of physicians, and should not exceed six weeks, at a maximum length. As aptly expressed by one educator respondent: " 5 initially but much longer if post graduate qualifications were to be offered. DO A LITTLE VERY WELL."

There should be no compromise to the quality of the courses, pretesting for content, relevance, duration, and overall satisfaction via a small pilot course, preferably to a combination of academic minded and busy practicing physicians may provide beneficial knowledge in this regard. The value of further exploration appears warrantee when one considers that in regards to course content and relevance, $100 \%$ of all respondents thought it as being either very important or important.

Therefore, the overall research findings indicated a marketing situation, wherein there is both a potential opportunity, and then a solution to match as well. Likewise, a recommendation would include further study for online institutions by using a large sample size before an actual venture into a niche area of physician business education. The recommendations made in this paper are possible options based on the evidence in literature and also from the discoveries of this exploratory research study. The findings of this study may serve as impetus for further practitioner research and scholarly inquiry.

\section{References}

1. Blank R (in press) Transformation of the US healthcare system: Why is change so difficult? Current Sociology 60(4): 415-426.

2. Kim J (2011) Pursuing an MBA: My personal journey as a physician executive, Physician Executive 37(2): 74-76.

3. Lazarus A (2009) Medical Leaders Wanted- Business Degree Desirable, Physician Executive 35(2): 40-42.

4. Saver D (2008) 'Just-in-time' business education for family physicians, Family Practice Management 15(5): 7-8.
5. Henry D (2004) ACAP: The headaches die down, Business week (3890): 105.

6. Fody K, Bagnal J (2004) HIPAA compliance not so great? Maybe it's time to coordinate, Healthcare Financial Management: Journal of the Healthcare Financial Management Association 58(6): 84.

7. Thomaselli R (2004) Novartis CEO says DTC requires CPR. Advertising Age 75(25): 3-29.

8. Bennett NL, Casebeer LL, Kristofco RE, Strasser SM (2004) Physicians' internet Information-seeking behaviors, Journal of Continuing Education in The Health Professions 24(1): 31-38

9. Kozlowski D (2002) Returning to school: an alternative to 'traditional' education, Orthopaedic Nursing/National Association of Orthopaedic Nurses. 21(4): 41-47.

10. Practice management (2004) physicians seeking to balance practice of medicine, business. Science Letter 1187.

11. Croasdale M (2005) Virtual medical group schools physicians in business skills American Medical News 48 (7): 1

12. Gerbarg Z (2002) Physician leaders of medical groups face increasing challenges, The Journal of Ambulatory Care Management 25(4): 1-6.

13. Angood PB (2013) All physicians are leaders, Physician Executive 39(2): 6-7.

14. Wilson J (2002) Leadership development: working together to enhance collaboration. Journal of Public Health Management and Practice: JPHMP 8(1): 21-26.

15. Wright K, Rowitz L, Merkle A (2001) A conceptual model for leadership development, Journal of Public Health Management and Practice: JPHMP. 7(4): 60-66.

16. Quintero JR (2002) Achieve cost benefits with innovative care management 33(4): 35-43.

17. Sullivan D (2000) Thought leaders (Book Review), Psychiatric Rehabilitation 24.

18. Management connections (2012) Physician relationship management in ASCs. Association of Operating Room Nurses. AORN Journal, 95(3).

19. Cooper DR, Schindler PS (2003) Business Research Methods (8th. ed., Rev.), New York NY: McGraw-Hill//rwin.

20. Lind DA, Marchal WG, Mason RD (2002) Statistical Techniques in Business \& Economics (11 ed., Rev.), New York: McGraw-Hill Irwin.

21. Anderson DR, Sweeney DJ, Williams TA (1999) Statistics for business and economics (Seventh Edition), Cincinnati, Ohio: South-Western College Publishing. 